\title{
A ESCALADA CONSERVADORA NO DEBATE EDUCACIONAL CONTEMPORÂNEO BRASILEIRO
}

\author{
Gabriel de Abreu Gonçalves de Paiva ${ }^{1}$
}

\begin{abstract}
RESUMO: As realizações educacionais no Brasil, historicamente, acompanharam o processo de consolidação da ordem capitalista nacional, refletindo suas mudanças e contradições. Nas últimas décadas, grupos conservadores, com o objetivo de projetar reformas, que não visam atender a construção de uma escola para todos, trabalham cotidianamente na construção de consensos em torno de um possível modelo ideal de educação. Na prática, projetos de lei, como o projeto "Escola sem Partido", são difundidos como necessários e fundamentais para a organização da atual educação brasileira, em combate a "doutrinação ideológica". Dentre os agrupamentos que realizam tal defesa encontra-se o Movimento Escola Sem Partido. Nesse sentido estamos sugerindo ler esses agrupamentos como aparelhos privados de hegemonia, os quais se propõem a organizar uma vontade coletiva, divulgando suas concepções ideológicas como interesses comuns de todos os brasileiros.
\end{abstract}

Palavras-Chave: Educação; Ações conservadoras; Escola Sem Partido; Brasil.

\section{CONSERVATIVE SCALING IN THE BRAZILIAN CONTEMPORARY EDUCATIONAL DEBATE}

\begin{abstract}
The educational achievements in Brazil, historically, have accompanied the process of consolidation of the national capitalist order, reflecting its changes and contradictions. In the last decades, conservative groups, with the purpose of designing reforms, which do not aim at building a school for all, work daily in the construction of consensuses around a possible ideal model of education. In practice, draft laws, such as the "School without a Party" project, are widespread as necessary and fundamental for the organization of the current Brazilian education, in the fight against "ideological indoctrination." Among the groupings that carry out such defense is the Movement Without Party School. In this sense we are suggesting to read these groupings as private devices of hegemony, which propose to organize a collective will, divulging their ideological conceptions as common interests of all Brazilians.
\end{abstract}

Keywords: Education; Conservative actions; School Without Party; Brazil.

\section{INTRODUÇÃO}

\footnotetext{
${ }^{1}$ Graduado em História, Especialista em História da Educação Brasileira. Mestre em Educação e Doutorando em História pela Universidade Estadual do Oeste do Paraná - UNIOESTE. Professor de História do Quadro Próprio do Magistério/SEED. Professor do Centro Universitário FAG, campus Toledo/PR. Contato: gabrielpaivahist@ yahoo.com.br.
} 
No ano de 2015, dois anos após as jornadas de junho de $2013^{2}$, já se tornou possível, de acordo com Calil (2016), reconhecer um novo elemento na conjuntura política brasileira: “[...] organizações e agrupamentos claramente reacionários lograram êxito em realizar manifestações massivas, convocadas em defesa do afastamento supostamente constitucional da presidente da República [...]” (2016, p.205-206). É inegável que aquelas manifestações foram massivas e que explicitaram uma capacidade de mobilização que, até então, a direita não possuía, "constituindo-se nas maiores

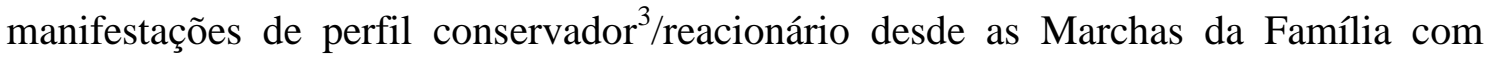
Deus pela Liberdade, realizadas em 1964" (Idem, p.206).

Esse período foi também caracterizado por intervenções conservadoras apresentadas ao Plenário da Câmara dos Deputados, como as ofensas de Jair Bolsonaro à Maria do Rosário quando "o deputado afirmou que não a estupraria porque ela não mereceria" (PINTO e LUCCIOLA, 2014); a Comissão especial para o Estatuto da Família, que definiu família apenas como a união entre homem e mulher e a assídua defesa da proposta que dificulta o atendimento a mulheres vítimas de agressão sexual, inclusive vetando que esta receba informações sobre seu direito ao aborto legal (MOURA, 2016).

Importa frisar, em relação àquele contexto, que o avanço da direita não se dava apenas nas manifestações de rua que reivindicavam o afastamento da presidente Dilma Rousseff, mas em atos concretos do governo da própria presidenta, como a imposição

\footnotetext{
${ }^{2}$ Em junho de 2013 ocorreram as maiores manifestações populares da história recente do Brasil, reunindo vários milhões de manifestantes, de diferentes estratos sociais e nas mais variadas regiões do país. O caráter pluriclassista, a diversidade de reivindicações e o fato de que a maior parte dos manifestantes não tinha nenhuma experiência política anterior propiciaram uma intensa disputa em torno dos rumos das mobilizações, podendo-se identificar ao menos três posições principais: a) a oposição de esquerda; b) a oposição conservadora em suas diferentes frações; c) os defensores do governo Dilma Roussef. A mídia corporativa oscilou entre a segunda e a terceira posição, sempre buscando diminuir o significado social dos protestos e apresentar as manifestações essencialmente como "anti-corrupção". (CALIL, 2013).

${ }^{3}$ Para Botelho e Ferreira "o conservadorismo é uma estrutura mental objetiva, dinâmica e condicionada historicamente. Estrutura objetiva, pois se trata de um modo de pensar e agir que de alguma forma transcende a subjetividade individual, por ser função do desenvolvimento da sociedade. Diferentemente do tradicionalismo, quase exclusivamente reativo, o conservadorismo moderno é coerente e reflexivo, pois surge como movimento consciente de oposição ao movimento "progressista", ou ao pensamento liberal-burguês." (2010, p. 11) Para BOTELHO e FERREIRA, é tradicional entre os conservadores "a importância dada à religião; a valorização das associações intermediárias situadas entre o Estado e os indivíduos (família, aldeia tradicional, corporação) e a correlata crítica à centralização estatal e ao individualismo moderno", bem como "o apreço às hierarquias e a aversão ao igualitarismo em suas várias manifestações; o espectro da desorganização social visto como consequência das mudanças vividas pela sociedade ocidental" (Idem, p.12).
} 
da Lei Antiterrorismo e da Agenda Brasil, que representaram "um retrocesso simultaneamente às liberdades democráticas e aos direitos sociais" (Idem, p.207).

Concomitantemente à escalada contra Dilma e aos avanços da direita, setores empresariais, religiosos, privatistas e reformadores passaram a intervir de forma mais assídua sobre as políticas educacionais, visando angariar adeptos e difundir seus projetos educacionais. Dentre esses projetos, pode-se citar o Projeto Escola Sem Partido e a Base Nacional Comum Curricular. De 2014 a 2017, foram 57 projetos de lei apresentados sob a matriz do Projeto Escola Sem Partido, de norte ao Sul do Brasil. (PROFESSORES CONTRA O ESCOLA SEM PARTIDO, 2018).

Nesse trabalho, abordaremos brevemente os principais Movimentos, os principais projetos voltados à educação em tramitação no Brasil, em especial o Movimento e o Projeto Escola Sem Partido, as possíveis aproximações com o Movimento pela Base Nacional Comum, as articulações e aproximações com os denominados think tanks ${ }^{4}$, diante de uma conjuntura, denominada por Demier (2018), de democracia blindada. Nossas reflexões, estruturadas nas obras de Gramsci (2004), baseiam-se na leitura desses agrupamentos como aparelhos privados de hegemonia, os quais se propõem a organizar, através da ação de seus intelectuais, uma vontade coletiva, divulgando suas concepções ideológicas como interesses comuns de todos os brasileiros. Ainda em Grasmci (2014) e Melo (2015), estamos diante de uma espécie de guerra de posição, cujas manobras combinam fundamentalismo religioso e fundamentalismo de mercado.

\section{AS AÇÕES CONSERVADORAS E OS PROJETOS EDUCACIONAIS EM TRAMITAÇÃO NO BRASIL}

No ano de 2015, elaborada pelo Movimento pela Base Nacional Comum, foi apresentada a primeira versão da Base Nacional Comum Curricular (BNCC) e no ano de 2016, ano do impeachment da presidente Dilma Rousseff, uma nova versão foi publicada. Em 20 de dezembro de 2017, ao final das atividades parlamentares, a BNCC foi homologada.

\footnotetext{
${ }^{4}$ Os think tanks, segundo Gros (2008, p.03), "se constituem em institutos privados de pesquisa que estão presentes no processo de formulação de políticas públicas, nos Estados Unidos e na Inglaterra, desde os anos 40, produzindo conhecimento sobre os temas sujeitos à regulamentação pública e, principalmente, formulando projetos de políticas públicas orientados pela doutrina do liberalismo".
} 
Depreende-se desse contexto que interpretações e visões de mundo conservadoras de diferentes matrizes vêm sendo crescentemente disseminadas há anos através de inúmeros aparelhos privados de hegemonia. (GRAMSCI, 2014). Para Calil (Idem, p.211),

[...] estes setores buscaram intervir em junho de 2013, tentaram disputar os rumos do movimento e promoveram agressões contra militantes de esquerda em vários lugares. Sem dúvidas, sua intervenção foi amplificada pela grande mídia, que buscou produzir lideranças conservadoras e construir uma interpretação para os protestos com sentido inteiramente antagônico às demandas sociais que deram origem às manifestações.

O movimento geral segue sendo de avanço conservador e isto tem uma razão muito concreta: não se trata de um movimento espontâneo, mas de uma ofensiva ideológica alicerçada em vasta rede de aparelhos privados de hegemonia, como é o caso do Movimento Escola Sem Partido e do Movimento pela Base Nacional Comum, que incluem desde páginas do Facebook até organizações interempresariais e envolvem abundantes recursos, contando com sólida estrutura organizativa. (Idem, p.212).

$$
\text { Inspirado no correspondente estadunidense "noindoctrination.org", o }
$$
Movimento Escola Sem Partido dispõe, hoje, de uma plataforma online ${ }^{6}$ na qual se delineia os caminhos de sua atuação. Em contrapartida, por essa mesma via, direcionam medidas de punição e inibição a professores que não atenderem as ideias, supostamente neutras, defendidas pelo programa. A plataforma justifica a criação do Movimento já que

\begin{abstract}
Vítima de um verdadeiro "sequestro intelectual", o estudante doutrinado quase sempre desenvolve, em relação ao professor/doutrinador, uma intensa ligação afetiva. Como já se disse a propósito da Síndrome de Estocolmo, dependendo do grau de sua identificação com o sequestrador, a vítima pode negar que o sequestrador esteja errado, admitindo que os possíveis
\end{abstract}

\footnotetext{
${ }^{5} \mathrm{O}$ fórum noindoctrination.org foi criado pela americana Luann Wright ao descobrir que o seu filho teria que escrever artigos sobre o racismo de brancos contra os negros. Wright acreditava que o professor do seu filho deveria tratar apenas de ensinar ele a escrever e não se aproveitar de sua posição para tratar de crenças pessoais em sala de aula. A solução encontrada por Wright foi fundar uma espécie de fórum, noindoctrination.org, para permitir que denúncias de pessoas que se sentissem afetadas pelas crenças de seus professores pudessem ser realizadas.

${ }^{6}$ A plataforma online é http://www.escolasempartido.org. Utilizaremos a plataforma wayback machine, uma ferramenta de busca disponibilizada pelo Internet Archive ( https://archive.org/web/) e que permite a consulta a versões antigas de sites, para consultas sobre as ações do Movimento de sua fundação aos dias de hoje.
} 


\begin{abstract}
libertadores e sua insistência em punir o sequestrador são, na verdade, os responsáveis por sua situação. De modo análogo, muitos estudantes não só se recusam a admitir que estão sendo manipulados por seus professores, como saem furiosos em sua defesa, quando alguém lhes demonstra o que está acontecendo (ESCOLA SEM PARTIDO, [s/d]a).
\end{abstract}

A denominada "doutrinação ideológica" também se fundamenta em uma pesquisa da Revista Veja, datada de 29 de agosto de 2008, na qual professores responderam a um questionário de apenas três questões, respectivamente: qual a principal missão da escola? Em sua opinião o discurso do professor é...? Com quem os professores mais de identificam. As respostas da primeira questão possuíam três objetivos constitucionais indissolúveis, ou seja, o correto seria assinalar as três resoluções e a segunda relacionava à formação para a cidadania. Apesar de argumentos indissociáveis, os professores questionados foram obrigados a responder apenas uma alternativa em cada questão. Percebe-se que as questões tentavam reduzir a política ao apartidarismo, o que não é considerado um equívoco, mas algo intencionalmente pensado a fim de sustentar a tese de "doutrinação ideológica" nas escolas.

Consta na plataforma online que o Movimento "é uma iniciativa conjunta de estudantes e pais preocupados com o grau de contaminação político-ideológica das escolas brasileiras, em todos os níveis: do ensino básico ao superior” (ESCOLA SEM PARTIDO, [s/d] b). Ainda, segundo o site, "a pretexto de transmitir aos alunos uma 'visão crítica' da realidade, um exército organizado de militantes travestidos de professores prevalece-se da liberdade de cátedra e da cortina de segredo das salas de aula para impingir-lhes a sua própria visão de mundo" (Idem, Ibidem).

Segundo Miguel (2016), apesar do discurso do movimento tentar criar para si uma imagem de defensor da escola contra o que chama de "contaminação políticoideológica”, o fundador do movimento, Miguel Nagib, possui vínculos com Instituto Millenium, tendo sido, por muito tempo, articulista e, posteriormente, um dos mantenedores do instituto. O Instituto Milenium é "o principal think tank da direita brasileira, criado em 2006 e financiado por empresas nacionais e transnacionais com eco na linha editorial de parte da grande imprensa e popularizada por jornalistas como Rodrigo Constantino" (MIGUEL, 2016, p. 593).

Ao disputar as orientações do Estado e ao tentar transformar interesses privados em públicos, o Movimento Escola Sem Partido, a partir do ano de 2014, passou a 
intensificar o embate político e ideológico e, no campo educacional, por vias parlamentares, passou a apresentar projetos com objetivos polêmicos, dentre os quais, limitar os conteúdos das disciplinas presentes no currículo nacional, criminalizar o trabalho docente e liquidar a liberdade de ensino.

O primeiro Projeto de Lei (PL) intitulado "Programa Escola Sem Partido" foi o PL 2974/2014 apresentado no Rio de Janeiro pelo deputado estadual Flávio Bolsonaro (PSC-RJ), atendendo um pedido de Miguel Nagib, que pedira ao parlamentar que formulasse um projeto com base em suas propostas. Em seguida, o vereador Carlos Bolsonaro propôs o PL 867/2014 na Câmara do Rio de Janeiro, com conteúdo praticamente igual ao já apresentado na esfera estadual. Desde então, a estratégia tem sido copiada por todo o país. Em nível federal os principais projetos foram os PLs 7180/2014, PL 7181/2014, PL 867/2015, PL 1411/2015, PL 1859/2015, PL 2731/2015, PL 5487/2016 e a PL 246/2019.

Para Melo (2015, p.04): “[...] estamos diante de uma espécie de guerra de posição, cujas manobras combinam fundamentalismo religioso e fundamentalismo de mercado [...]". Reforçando tal ideia, Gramsci (2014, p.24), assegura que "a estrutura maciça das democracias modernas [...] constitui para a arte política algo similar as "trincheiras" e as fortificações permanentes da frente de combate na guerra de posição [...]" constituídas pelos grupos dominantes, cujo avanço é facilitado pela inexistência das classes trabalhadoras no campo e pelas estruturas organizativas de semelhante dimensão. Sendo assim, para Calil, (Idem, p.213)

É inegável que há um avanço ideológico de posições socialmente conservadoras, culturalmente obscurantistas e economicamente liberais e antipopulares, aliado a uma expressiva popularização de intelectuais e lideranças políticas que podem ser caracterizadas como de extrema-direita, defendendo posições fascistizantes e um discurso violentamente antipopular.

O que se coloca em pauta, portanto, é a contínua e progressiva restrição das liberdades democráticas e dos direitos constitucionalmente garantidos e o fortalecimento do aparelho repressivo, da privatização e da censura nas estruturas educacionais, da criminalização do trabalho docente, dentre outras ações. O fim do direito à educação e a limitação ao direito à aprendizagem - propagados como sinônimos - individualiza o fracasso ou o sucesso, nega os direitos a eles atrelados, 
como política para transporte escolar, política de merenda escolar, política de garantia de acesso e permanência, dentre outras políticas, privatizando assim, parte expressiva das atuais responsabilidades do Estado.

Pode-se perceber as características da atual conjuntura política ao verificar as organizações e movimentos que, por exemplo, dão apoio institucional à ONG Movimento pela Base Nacional Comum - Todos pela Base, elaboradores da BNCC: Abave, Cenpec, Comunidade Educativa Cedac, Consed, Fundação Lemann, Fundação Maria Cecilia Souto Vidigal, Fundação Roberto Marinho, Instituto Ayrton Senna, Instituto Inspirare, Instituto Natura, Instituto Unibanco, Itaú BBA, Todos Pela Educação, Undime. ${ }^{7}$ Estes são os grupos fomentadores de projetos que defendem a padronização e o controle do que é considerado cultura escolar, bem como, modificações nos padrões de gestão escolar, no currículo escolar, na elaboração de materiais pedagógicos e na formação de professores. ${ }^{8}$ Tais ações ocorrem de forma evidente, o que para Dias (2012, p.129)

Trata-se da captura da subjetividade dos antagonistas. A burguesia tratou, com grande êxito de transformar-se em horizonte ideológico, político e econômico da história. Tudo e todos estavam (e estão) submetido a esse processo, de deshistoricização. A vida é vida burguesa, como burguesas são a família, a escola e o trabalho, lugares privilegiados de socialização onde os subalternos são moldados.

Metodologicamente, análises como estas exigem muito cuidado, pois existe mais heterogenia, ou seja, diferenças e desacordos importantes que precisam ser desvendadas entre as principais organizações de direita. Compreende-se que, efetivamente, ocorre o deslizamento do liberalismo para posições cada vez mais repressivas e tal processo se materializa no progressivo fechamento dos espaços de liberdade sem ruptura com os parâmetros formais da democracia liberal e na configuração de uma democracia blindada. Entretanto, o quão unificadas são, de fato, as ideologias é uma questão a ser discutida. Para Eagleton (1997, p.51):

\footnotetext{
${ }^{7}$ Veja a lista completa de integrantes no http://movimentopelabase.org.br/quem-somos/ (MOVIMENTO PELA BASE NACIONAL COMUM, [s/d]).

${ }^{8}$ No final de 2017, no contexto de aprovação da Emenda Constitucional 95, o governo federal liberou, para o ano de 2018, 100 milhões para apoiar estados e municípios na implementação da BNCC (BEZERRA, 2017).
} 


\begin{abstract}
As ideologias são, de modo geral, formações diferenciadas, internamente complexas, com conflitos entre seus vários elementos que precisam ser continuamente renegociados e resolvidos. Aquilo que chamamos de ideologia dominante é tipicamente a ideologia de um bloco social dominante, formado de classes e facções cujos interesses nem sempre estão de acordo, e essas concessões e divisões irão se refletir na própria ideologia. Pode-se dizer, com efeito, que parte da força da ideologia burguesa reside no fato de ela "falar" a partir de uma multiplicidade de situações, e por ser assim sutilmente difusa não oferece nenhum alvo isolado a seus antagonistas. De modo semelhante, as ideologias oposicionistas geralmente refletem uma aliança provisória entre diversas forças radicais.
\end{abstract}

Tais ações se materializam em projetos funcionais que, porventura, não são elaborados coletivamente, mas acabam incorporados como pauta por inúmeros grupos, portanto não se caracteriza como uma frente única dentre os mesmos. Nas palavras de Eagleton (Idem, p.36) “[...] crenças que são funcionais para um grupo social não precisam ser motivadas dentro do próprio grupo; elas podem simplesmente cair no seu colo, por assim dizer. Formas de consciência funcionais para uma classe social podem também ser funcionais para outra de interesses opostos".

Para exemplificar tal argumento, pode-se tomar como exemplo algumas das justificativas presentes tanto na BNCC quanto nos projetos defendidos pelo Movimento Escola Sem Partido. O Movimento Escola Sem Partido foi criado no ano de 2003 a partir de uma pauta anticomunista, mas em meio a uma expressiva mobilização de religiosos diante do denominado "kit-gay", o Movimento passou a adotar como pauta de combate a denominada "ideologia de gênero", o que alavancou sua popularidade. É mister assinalar que tanto o Movimento Escola Sem Partido quanto o Movimento pela Base Nacional Comum julgam como um dos responsáveis pelo "fracasso educacional" o profissional docente, culpabilizando-o pelos resultados considerados inadequados nas avaliações nacionais (como o SAEB, por exemplo). Tal culpabilização se fundamenta na ideia de que os professores teorizam demais e possuem atitudes descompassadas como, por exemplo, a "doutrinação ideológica".

Dessa maneira, é seguro afirmar que a escalada repressiva envolve três movimentos paralelos: a mudança na legislação, a reinterpretação restritiva da legislação existente e a atuação repressiva realizada à margem da lei ou produzindo interpretações claramente arbitrárias, aspecto que pode ser visualizado nos exemplos acima mencionados. 
Para Gros (2008, p.03), o avanço do movimento ideológico se desenvolveu "através da formação de redes de articulação entre intelectuais, acadêmicos e suas publicações, empresas jornalísticas, organizações empresariais e um novo tipo de institutos privados de pesquisa sobre políticas públicas, os think tanks". De acordo com Hoeveler (2015, p.02), “com a conquista de posições ao longo dos anos 1970, começam a formar-se ainda nessa década os think-tanks (tanques de pensamento) de orientação marcadamente neoliberal". Neste sentido, entende-se que a atuação dos aparelhos privados de hegemonia se configura como ações partidárias à medida que se pretendem organizadores de uma vontade coletiva e agem estrategicamente para implementá-la. Para compreender a atuação partidária desses agrupamentos

[...] será necessário levar em conta o grupo social do qual o partido é expressão e a parte mais avançada: ou seja, a história de um partido não poderá deixar de ser a história de um determinado grupo social. Mas esse grupo não é isolado; tem amigos, afins, adversários, inimigos. Somente no quadro global de todo o conjunto social e estatal (e, frequentemente, também com interferências internacionais) é que resultará a história de um determinado partido [...] (GRAMSCI, 2014. p.88).

Panebianco (1982), afirmou que todo partido político constituído por um programa e por uma ideologia é uma instância de poder que almeja o poder político, não sendo, necessariamente, o poder estatal. Nessa concepção, o partido poderá realizar uma disputa interna ou externa ao aparelho do Estado e o que estará em jogo não será apenas um modelo educacional, mas sim a defesa de um projeto de sociedade.

A concepção integral de Estado formulada por Gramsci buscou dar conta da compreensão de como as classes dominantes organizam seus interesses visando ao exercício de sua dominação da forma mais ampla possível. Para Mattos:

\footnotetext{
Tais classes dominantes não apenas monopolizam agências de governo para garantir seus interesses (embora o façam), mas, para tanto, já se encontram organizadas em espaços da sociedade civil - associações, sindicatos, clubes, ONGs, fundações privadas etc. - onde fortalecem seus laços de unidade entre os que defendem as suas propostas como de interesse geral (nacional, de todos, dos cidadãos etc.) e a partir daí, estabelecem consensos, que muitas vezes incluem setores dominados que aceitam tais propostas como se fossem suas (2016, p.229).
} 
Em Gramsci, o Estado, em seu sentido ampliado, é compreendido a partir da "dupla perspectiva" na ação política e na vida estatal.

\begin{abstract}
Vários graus nos quais se pode apresentar a dupla perspectiva, dos mais elementares aos mais complexos, mas que podem ser reduzidos teoricamente a dois graus fundamentais [...] da força e do consenso, da autoridade e da hegemonia, da violência e da civilidade, do movimento individual e daquele universal (da "Igreja" e do "Estado"), da agitação e da propaganda, da tática e da estratégia, etc. (GRAMSCI, 2014, p.33-34).
\end{abstract}

A atuação, em sentido ampliado, visa a definir a aplicação de um determinado projeto hegemônico, isto é, combinar de forma equilibrada elementos de consenso e coerção. Em Gramsci, o conceito de hegemonia aparece não apenas como sinônimo de consenso, mas “[...] caracteriza-se pela combinação de força e consenso, que se equilibram de modo variado, sem que a força suplante em muito o consenso, mas, ao contrário, tentando fazer com que a força pareça apoiada no consenso da maioria, expresso pelos chamados órgãos da opinião pública -, os quais, por isso, em certas situações, são artificialmente multiplicados.” (GRAMSCI, 2014, p.96).

Gramsci normalmente usa a palavra hegemonia para designar a maneira como um poder governante conquista o consentimento dos subjugados e os subordina - apesar de, é verdade, empregar o termo ocasionalmente para designar conjuntamente o consentimento e a coerção. Corroborando essa ideia, para Eagleton $(1997,105)$ a hegemonia também é uma categoria mais ampla que a ideologia, pois:

[...] inclui a ideologia, mas não pode ser reduzida a ela. Um grupo ou classe dominante pode assegurar o consentimento a seu poder por meios ideológicos, mas também pode fazê-lo, digamos, alterando o sistema de tributação de maneira favorável aos grupos de cujo apoio necessita ou criando uma camada de operários relativamente opulenta e, portanto, razoavelmente inerte. Ou a hegemonia pode assumir antes formas políticas que econômicas: o sistema parlamentar nas democracias ocidentais é um aspecto crucial de tal poder, já que reforça a ilusão de autogovemo por parte do populacho. O que distingue de maneira única a forma política de tais sociedades é que se espera que as pessoas acreditem que governam a si mesmas, uma crença que não era esperada de um escravo da Antigüidade ou de um servo da Idade Média.

Para Felipe Demier (2017), as características apontadas até então e as formas de organização do Estado, orquestradas numa proposição hegemônica, demonstram que 
estamos vivenciando democracias blindadas, que possuem nos meios de comunicação de massa e nos grandes conglomerados empresariais-midiáticos uma de suas principais fontes de produção do consenso. Para Demier (2017) "essa concepção neoliberal, privatista, das relações entre sujeito, sociedade e Estado, instilada diariamente pelos aparelhos privados de hegemonia (não só midiáticos) e que, introjetada pelas massas, molda nestas uma subjetividade individualista e predatória [...]”, atualmente fortemente usufruída para aplicação de um projeto privatista de sujeito e de Estado.

\section{CONSIDERAÇÕES FINAIS}

Até o momento, compreendemos que o debate acerca da necessidade de mudanças na estrutura educacional e os problemas vivenciados no país são utilizados por aparelhos privados de hegemonia, como o Movimento Escola Sem Partido e o Movimento pela Base Comum, cuja função é a de projetar e aplicar interesses privados, propagandeados como consensuais, em espaços educacionais, principalmente públicos. Essa é a plataforma para que esses projetos alcancem a sociedade política e sejam executados como políticas públicas que se apresentem sob a máscara de interesses gerais. Isso sem abrir mão dos instrumentos coercitivos de que dispõe esse Estado para reprimir os descontentes e manter sob controle o conjunto dos dominados.

Nas palavras de Ramos “a educação, necessariamente e sempre, será guiada por alguma filosofia, por uma concepção de mundo, mesmo que não sejam explicitados nos respectivos projetos político-pedagógicos [...]" (2016, p.02), ou seja, não há neutralidade na educação. Corroborando essa ideia e ampliando a argumentação, Frigotto pondera que o Movimento Escola Sem Partido:

[...] trata-se da defesa, por seus arautos, da escola do partido absoluto e único: partido da intolerância com as diferentes ou antagônicas visões de mundo, de conhecimento, de educação, de justiça, de liberdade; partido, portanto da xenofobia nas suas diferentes facetas: de gênero, de etnia, da pobreza e dos pobres, etc. Um partido, portanto que ameaça os fundamentos da liberdade e da democracia liberal, mesmo que nos seus marcos limitados e mais formais que reais. Um partido que dissemina o ódio, a intolerância e, no limite, conduzirá eliminação do diferente (2016, p. 12). 
A falta de neutralidade parece explícita quando, através do Movimento Escola Sem Partido, defende-se apenas a difusão de ideais considerados coerentes para o grupo, impondo, dessa maneira, limitações ao currículo trabalhado no espaço escolar. Através de projetos de lei como os acima citados, os profissionais da educação sofreriam uma flagrante violação de direitos fundamentais, especialmente no que se refere ao direito à liberdade de ensino, censurando e criminalizando o seu trabalho.

Para Eagleton (1997), a suposta neutralidade do Estado é uma poderosa fonte da hegemonia política, afinal compreende que esta, na verdade, não é simplesmente uma ilusão ideológica, pois "na sociedade capitalista, o poder político é relativamente autônomo diante da vida social e econômica, ao contrário da organização política das formações pré-capitalistas.” (Idem, p.105). Acerca dessa problemática, Melo argumenta que

o ponto que nos parece importante explorar liga-se ao fato desta ser mais uma entre tantas outras campanhas ideológicas da nova direita, e que destinasse a produzir resultados muito mais profundos do que uma mera aprovação de uma legislação que teria muitas dificuldades para ser implementada, salvo se fosse acompanhada por uma espécie de histeria coletiva onde estudantes denunciariam os professores doutrinadores", que nos termos desta legislação podem cumprir pena de até dois anos no cárcere $(2015, \text { p. } 2)^{9}$.

Como afirmou Melo (2015, p. 2), o elemento mais assustador é a adesão aos projetos citados e a sua aceitação, pois o conjunto de leis, sucintamente apresentados, parece representar um retrocesso para a educação brasileira:

[...] estamos agora às voltas com um movimento patrocinado por setores obscurantistas que se interessam em promover uma espécie de macarthismo, mobilizando alunos, pais, mães e responsáveis, além, infelizmente de alguns professores, numa histeria paranoica contra a 'doutrinação' (MELO, 2017, p. $1)$.

Cabe ressaltar que os projetos de lei citados não representam nenhuma novidade para a educação brasileira e acerca dessa questão, Salles (2016) observa que passado e presente se encontram permeados por novas estratégias de controle, de acordo com os

\footnotetext{
${ }^{9}$ Para Melo (2015, p. 3), o propósito de campanhas como estas é o de interditar a possibilidade da crítica, da construção do conhecimento crítico, fundamental para o desenvolvimento científico e do processo pedagógico. Isso é bastante evidente em outra campanha protagonizada por esta nova direita, a "Mais Mises, Menos Marx”, campanha que possui natureza profundamente anticientífica e antidemocrática. 
interesses do sistema capitalista. De outro modo, compreende-se, a partir das leituras de Gramsci, (2004), que os organizadores dos Movimentos se apresentam como intelectuais orgânicos da classe que, ao fundamentar e praticar os ideais defendidos pelos Movimentos, interpretados como aparelhos privados de hegemonia, procuram realizar a manutenção da hegemonia burguesa.

Para Gramsci, os intelectuais possuem papel fundamental no exercício efetivo da hegemonia, pois organizam e conferem legitimidade aos dois movimentos centrais de organização da cultura: o do consenso "espontâneo" e o do aparelho de coerção estatal. Dessa forma, segundo Gramsci (2014), o exercício da hegemonia seriam articulados junto aos aparelhos privados de hegemonia, que na verdade são instituições criadas para a formação do consenso. Os aparelhos privados de hegemonia funcionam como mantenedores das posições de uma determinada classe na guerra de posição. Na perspectiva do autor, a disputa pela hegemonia numa sociedade, isto é, pelo poder político e pelo convencimento ideológico será tão mais rápida e eficaz quanto mais capaz for um grupo de elaborar simultaneamente seus próprios intelectuais orgânicos.

Importa frisar que, desde 2014, o Movimento se popularizou por meio de projetos de lei apresentados nas diversas esferas (municipais, estaduais e nacional), embora atue em outra frente, em especial nas redes sociais, através da construção de consensos sobre a população. A atuação do Movimento Escola Sem Partido se realiza no âmbito da sociedade civil, esfera da sociedade que engloba o conjunto das organizações responsáveis pela difusão e/ou elaboração das ideologias, incluindo escolas, Igrejas, partidos, sindicatos e meios de comunicação. Sendo assim, um aspecto determinante para a compreensão do Movimento Escola Sem Partido é a noção de ideologia defendida. Portanto, parece seguro afirmar que o Movimento Escola Sem Partido visa também a construir um consenso por meio de suas redes sociais visando ao controle social.

Por esta razão, o Movimento Escola Sem Partido cumpre uma função essencial na manutenção da dominação de classe: à medida que busca assegurar a hegemonia de sua visão de mundo, por meio da escola, atua no âmbito da sociedade civil, exercendo uma pressão sobre a chamada sociedade política.

\section{BIBLIOGRAFIA}

Programas de Pós-Graduação em Ciências Sociais e Filosofia - UNIOESTE - Rua da 
BEZERRA, M. MEC homologa Base Curricular e anuncia $\mathbf{R} \$ 100$ milhões para sua aplicação. 2017. Disponível em <https://educacao.uol.com.br/noticias/2017/12/20/mechomologa-base-curricular-e-anuncia-r-100-milhoes-para-sua-aplicacao.htm>. Acesso em: 01 set. 2018.

BOTELHO, A.; FERREIRA, G. N.. Revendo o pensamento conservador. In: FERREIRA, G. N.; BOTELHO, A. (Org). Revisão do pensamento conservador: ideias e políticas no Brasil. São Paulo: Hucitec / Fapesp, 2010.

BRASIL. Constituição da República Federativa do Brasil. 1988. Disponível em <http://www.planalto.gov.br/ccivil_03/Constituicao/Constituicao.htm>. Acesso em: 25 mar. 2016.

CALIL, G. Embates e disputas em torno das jornadas de junho. Projeto História, São Paulo, n. 47, pp. 377-403, Ago. 2013.

CALIL, G. Estado, Capitalismo e Democracia no Brasil recente. In: SILVA, C. L.; CALIL, G.; SILVA, M. A. B. (Org). Ditaduras, transição e democracias: estudos sobre a dominação burguesa no Brasil contemporâneo. Porto Alegre: FCM Editora, 2016.

DEMIER, F. Para além da democracia blindada? Contrarreformas, consenso e coerção no Brasil atual. $2017 . \quad$ Disponível em $<$ https://esquerdaonline.com.br/2017/11/25/para-alem-da-democracia-blindadacontrarreformas-consenso-e-coercao-no-brasil-atual/>. Acesso em: 06 set. 2018.

DIAS, E. F. Revolução passiva e modo de vida. Ensaios sobre as classes subalternas, o capitalismo e a hegemonia. São Paulo: Editora José Luís e Rosa Sundermann, 2012.

EAGLETON, T. Ideologia: uma introdução. São Paulo: Editora da Universidade Estadual Paulista: Editora Boitempo, 1997.

ESCOLA SEM PARTIDO. Escola sem partido: educação sem doutrinação. [s/d]. Disponível em: <http://www.escolasempartido.org/>. Acesso em: 18 maio 2017.

ESCOLA SEM PARTIDO. Síndrome de estocolmo. [s/d] a. Disponível em <http://www.escolasempartido.org/sindrome-de-estocolmo>. Acesso em: 05 set. 2018.

ESCOLA SEM PARTIDO. Quem somos. [s/d] b. Disponível em <http://www.escolasempartido.org/quem-somos>. Acesso em: 05 set. 2018.

FONTES, V. O Brasil e o capital imperialismo: teoria e história. Rio de Janeiro: EPSJV/Editora UFRJ, 2010. 
FRIGOTTO, G. "Escola sem partido": imposição da mordaça aos educadores. 2016. Disponível em <https://espacoacademico.wordpress.com/2016/06/29/escola-sempartido-imposicao-da-mordaca-aos-educadores/>. Acesso em: 18 maio 2017.

GRAMSCI, A. Cadernos do cárcere. Vol. 2. Os intelectuais. O princípio educativo. Jornalismo. Rio de Janeiro: Civilização Brasileira, 2004.

GRAMSCI, A. Cadernos do cárcere. Vol. 3. Maquiavel. Notas sobre o Estado e a Política. Rio de Janeiro: Civilização Brasileira, 2014.

GROS, D. B. Considerações sobre o neoliberalismo como movimento ideológico internacional. $2008 . \quad$ Disponível em <http://revistas.fee.tche.br/index.php/ensaios/article/view/2188>. Acesso em: 18 maio 2017.

HOEVELER, R. Tropa de elite do neoliberalismo (2): a direita transnacional, $\begin{array}{llll}\text { ontem } & \text { e hoje. } & 2015 . & \text { Disponível }\end{array}$ <https://capitalismoemdesencanto.wordpress.com/2015/06/03/tropa-de-elite-doneoliberalismo-2-a-direita-transnacional-ontem-e-hoje/>. Acesso em: 25 maio 2017.

MATTOS, M. B. Estado, Hegemonia e Classe Trabalhadora (a partir do Brasil atual). In: SILVA, C. L.; CALIL, G.; SILVA, M. A. B. (Org). Ditaduras, transição e democracias: estudos sobre a dominação burguesa no Brasil contemporâneo. Porto Alegre: FCM Editora, 2016.

MELO, D. "Escola sem partido" ou escola com "partido único"? 2015. Disponível em <http://blogjunho.com.br/escola-sem-partido-ou-escola-com-partido-unico/>. Acesso em 18 maio 2017.

MELO, D. A batalha pelo futuro: contra o projeto Escola Sem Partido. 2017. Disponível em <http://blogjunho.com.br/a-batalha-pelo-futuro-contra-o-projeto-escola-sem-partido/>. Acesso em: 18 maio 2017.

MIGUEL, L. F. Da "doutrinação marxista" à "ideologia de gênero": escola sem partido e as leis da mordaça no parlamento brasileiro. Direito e Práxis. Rio de Janeiro, V. 7, N.15, 2016. Disponível em: <http://www.epublicacoes.uerj.br/index.php/revistaceaju/article/view/25163>. Acesso em: $10 \mathrm{dez}$. 2017.

MOURA, F. P. de. "Escola Sem Partido": relações entre Estado, educação e religião e os impactos no ensino de história. 189 f. Dissertação (Mestrado Profissional em Ensino de História) Instituto de História, Universidade Federal do Rio de Janeiro, Rio de Janeiro, 2016.

PANEBIANCO, A. Modelos de partido. Organización y poder em los partidos políticos. Madri: Alianza Editorial, 1982. 
PINTO, A. C.; LUCCIOLA, L. Jair Bolsonaro repete insulto a deputada Maria do Rosário: 'Só não te estupro porque você não merece'. Extra Online, 09 dez. 2014. Disponível em: <https://extra.globo.com/noticias/brasil/jair-bolsonaro-repete-insultodeputada-maria-do-rosario-so-nao-te-estupro-porque-voce-nao-merece14781338.html>. Acesso em: 15 jul. 2019.

PRESIDÊNCIA DA REPÚBLICA. Medida Provisória n⿳ 746, de 22 de setembro de 2016. 2016. Disponível em <https://www.planalto.gov.br/ccivil_03/_Ato20152018/2016/Mpv/mpv746.htm>. Acesso em: 02 nov. 2016.

PROFESSORES CONTRA O ESCOLA SEM PARTIDO. Vigiando os Projetos de Lei. Disponível em $<$ https://professorescontraoescolasempartido.wordpress.com/vigiando-os-projetos-delei/>. Acesso em: 06 set. 2018.

PROGRAMA ESCOLA SEM PARTIDO. Por uma lei contra o abuso da liberdade de ensinar. [s/d]. Disponível em <http://www.programaescolasempartido.org/>. Acesso em: 18 maio 2017.

RAMOS, M. N. "Escola sem partido": a criminalização do trabalho pedagógico. 2016. Disponível em <http://www.anped.org.br/news/escola-sem-partidocriminalizacao-do-trabalho-pedagogico>. Acesso em: 18 maio 2017. 